\author{
V International Forum on Teacher Education
}

\title{
Development of Future Primary School Teachers' Linguistic and Methodological Competence
}

\author{
Irina V. Khairova* (a), Venera G. Zakirova (b)
}

(a), (b) Kazan Federal University, 420008, Kazan (Russia), 18 Kremlyovskaya street

\begin{abstract}
Many Russian and foreign researchers note the inability to apply theoretical knowledge in practice, the gap between theory and practice in the context of university studies as one of the reasons of difficulties in the implementation of young teachers' professional activities. The competence approach implemented in the education system of Russia today offers a solution to this problem through the formation of special, general and key competencies. Primary school teachers' professional competence also includes a range of private methodological competencies. One of these competencies is linguistic and methodological, which ensures a teacher's readiness to teach the Russian language to primary school students. Often the value of particular methodological competencies is underestimated. In this article, the importance of linguistic and methodological competence in ensuring the achievement of a new quality of education is revealed through the comparative analysis of two lessons. The purpose of this article is to define strategies and develop tactics for the formation of elementary school teachers' linguistic and methodological competence in the context of continuous pedagogical education. The leading method of the research was a pedagogical experiment conducted among students and primary school teachers. The article describes the main stages of the experiment, presents the tactics of cognitive and projective strategies implementation in the context of university training for bachelor's students - future primary school teachers, and advanced courses for primary school teachers. Digital educational resources, distance learning modules, activity-related educational technologies are considered as the main tools and tactics. The materials presented in the article allow increasing the effectiveness of teachers' professional activity in the field of language education.
\end{abstract}

Keywords: linguistic and methodological competence; language education of younger schoolchildren; strategies and tactics of linguistic and methodical training of students and primary school teachers; digital educational resources; distance learning.

\section{(C) 2019 Irina V. Khairova, Venera G. Zakirova}

This is an open access article distributed under the terms of the Creative Commons Attribution License (CC BY 4.0), which permits unrestricted use, distribution, and reproduction in any medium, provided the original author and source are credited.

Published by Kazan Federal University and peer-reviewed under responsibility of IFTE-2019 (V International Forum on Teacher Education) 


\section{Introduction}

Analyzing the problems of young teachers' social and professional adaptation, many Russian and foreign scientists mention the inability to apply theoretical knowledge in practice and the gap between theory and practice in the context of university education as a reason of difficulties in carrying out professional activities. Modern Russian psychological, pedagogical and methodical studies are dedicated to search for the ways of bringing together vocational training with real pedagogical activity, i.e. strengthening the practical focus of teacher training, development of practice-oriented models of future teachers' training.

The competency-based approach implemented in Russian universities aims to solve these problems. According to it, teachers' professional competence is understood as an integral characteristic that determines a specialist ability to solve typical professional tasks arising in different situations of pedagogical activity on the basis of acquired knowledge and professional experience.

The primary school teachers' professional activity is distinguished by a considerable amount of disciplines they teach, and their professional competence consists of a set of psychological and pedagogical and particular methodological competencies. One of these competencies is linguistic and methodological, which ensures the teacher readiness to teach the Russian language to elementary school students. Linguistic and methodological competence is understood as an ability to successfully carry out methodological activities on language education of primary schoolchildren in a new information environment on the basis of acquired knowledge and initial experience and with regard to the standards requirements (Kurlygina, 2012).

At the same time practice analysis (questionnaire of student teachers, attendance and analysis of their lectures, as well as interaction with primary school teachers in the system of advanced training, analysis of their lessons) demonstrates an insufficient level of linguistic and methodological competence of both students and young specialists, their reluctance to carry out language education of primary schoolchildren in the context of activity paradigm. Scientific and theoretical analysis of teacher preparation practice revealed such weaknesses as the non-use of problem methods of teaching and interactive technologies which involve students in the intellectual activity and development of their initiative and responsibility. All that as a whole restrains a full realization of competency-based model for training of bachelor's students majoring in teacher education. The revealed contradictions determined the relevance of the research topic.

\section{Purpose and objectives of the study}

The purpose of the study is to determine strategies and develop tactics for the formation of primary school teachers' linguistic and methodological competence in the context of continuing pedagogical education.

\section{Literature review}

In the last decades research studies on the identification of strategies and tactics which form the competencies that prepare pedagogical university graduates to carry out their professional activity has become relevant.

In the sphere of Russian language teaching it is specifically connected to linguistic and methodological competence. In his research, Lvov (2007) has specified the components of competence. He distinguished personal qualities such as philological education, speech culture, spiritual and educational 
interests etc.; and professional qualities which include subject knowledge, an ability to write compositions, work with texts etc., and methodological abilities, i.e. to choose studying materials and use them correctly, to identify the reasons for students' gaps in knowledge and their abilities, to correct and prevent them.

Sinichkina (2010) defines linguistic and methodological competence as the base in the structure of professional competence of a language teacher and distinguishes its three main components: axiological, cognitive, and operational activity. According to the author, they serve as a vector for the formation of linguistic and methodological competence, defining the purpose and content of the future pedagogical activity of a Russian language teacher.

A study by Isaeva (2016) focuses on the formation of linguistic and methodological competence among future teachers of Russian language. The scientist develops two key strategies for linguistic and methodological training of bachelor's, ensuring the development of linguistic and methodological thinking and readiness for practical activities in teaching Russian to schoolchildren in the context of new standards introduction. According to the author, such strategies include a cognitive approach focused on mastering basic competences, providing the theoretical and methodological basis for professional pedagogical activity, and a projective strategy aimed at mastering practical competence. The issues of linguistic and methodological competence formation are also considered in the context of professional training of primary school teachers.

In this respect, we are particularly interested in the study of Kurlygina (2012). The researcher conducts a component analysis of teacher methodological activities in relation to the competencies that ensure the formation of linguistic and methodological competence. As a means of linguistic and methodological competence formation, the scholar considers linguistic and methodological tasks as models of real pedagogical situations that ensure the initial (starting) readiness of a pedagogical university graduate for methodological activities in teaching Russian to schoolchildren.

The issues of effective professional training of teachers are thoroughly studied by foreign researchers. A review of publications on teacher training from 2000 to 2010 is presented in the article written by Avalos (2011). At the end of the review, the scientist draws a conclusion how the production brings out the complexities of teacher professional learning and how research and development have taken cognisance of these factors and provided food for optimism about their effects, although not yet about their sustainability in time.

A study by Opfer and Pedder (2011) is dedicated to the problem of teacher professional development. The scientists distinguish three subsystems - teacher, school, and learning activity - and describe how elements of these subsystems interact and can be combined in different ways. As a result, they influence teacher learning with a varying intensity. The authors conclude that to understand teacher learning researchers must implement methodological practices that focus on the reciprocal influences of all three subsystems.

Professional competence was a research topic in the study done by Dante Guerrero and Gerson La Rosa (2013). In the article, the authors give an approximation of the intellectual structure of research related to teacher professional competence. Using scientific domain analysis, a new paradigm of information science, the authors studied a number of publications in journals listed in the multidisciplinary databases: "Web of Science" and "Scopus" from 1950 to mid-2012. The maps generated using the scientific visualization software "Citespace II" allowed visualizing the scope of research, specific features and directions of the professional competences. 


\section{Methodology}

The research uses a complex of theoretical and practical teaching methods: analysis of the theory and practice of teaching, teaching of lower grades in the mode of course preparation; bachelor students and teachers survey in order to form their linguistic and methodological competence; analysis of teachers' and students' lessons.

The need to improve the linguistic and methodological competence of in-service teachers is confirmed by the analysis of their lessons.

The following comparative analysis of two lessons of two different teachers (teacher A, teacher B) on the same topic of studying a "Silent consonants" rule shows the crucial role of linguistic and methodological competence in ensuring the effectiveness of the Russian language lesson on achieving subject and meta-subject results.

Both teachers plan their lesson in the activity paradigm. Teachers do not state the rule directly, but organize the process so that students discover and formulate a new spelling rule. From the didactic point of view, all stages of the new knowledge acquisition are consistently maintained in teacher A's and teacher B's lessons. However, in the teacher A's lesson, children are more cognitive, independent in their opinions; they carry out analytical work with language material, and consciously formulate the rule through a set of questions, etc. It can be confidently said that the teacher A's lesson on the achievement of subject and meta-subject results is more effective. In terms of linguistic correctness and methodological literacy, the teacher B's lesson is in many ways inferior. We begin with the stage of knowledge actualization. Teacher A chooses only four words for work, each of them has only one orthogram, which pupils must determine and correctly solve the spelling problem through selection of a check word. However, working with these four words, the teacher repeats a large amount of information, and moreover, makes an important generalization: two different orthograms (checked unstressed vowels in the word root and paired voiced and deaf consonants in the word root), and only one way to solve a spelling task. This is a demonstration of the phonemic principle of Russian orthography, and based on it the teacher skillfully teaches children paying their attention to important key positions, forming children's correct understanding of Russian orthography and, as a result, children's orthographic literacy. The teacher also considers the new spelling rule in the context of this principle, which ensures consistency in students' orthographic knowledge and skills formation. At this stage of the lesson, teacher B chooses a task that is rather effective in terms of meta-subject and subject skills formation, which leads to the necessity to learn new material through a trial study action. The educator suggests students to divide the words on the blackboard into spelling groups, hiding among these words a word that contains an orthogram which children have not yet studied. However, among ten suggested words four contain two orthograms at once. Children do not know what to do and where to put these words. As the result, an excellent didactic idea turns out to be a failure due to the teacher's poorly formed linguistic and methodological competence. By offering students to formulate independently the rule, both teachers organize observation of language material. Teacher A chooses words well-known to children, such as kapustniy (“cabbage"), grustniy ("sad"), radostniy ("happy"), zvezdniy ("stellar") etc. The tutor suggests the children to copy these words from the blackboard into their notebooks, pronouncing them out loud (orthographic pronunciation is widely used in the practice of learning Russian orthography), and asks a question: "What did you notice when writing these words?" This question does not cause any problems for children. Everyone noticed that the words contained letters which were not pronounced. In such a way, the children learn about the topic (Silent consonants) and the main question: Can we check them? Then, the teacher gets the children back to the beginning of the lesson. How 
did they check two orthograms (selected check words)? And the solution is found by itself: is it possible to solve this spelling problem in the same way? Children now can easily choose check words which are familiar to them. After that, children formulate the rule, read an article, compare their version with the rule in the textbook and add necessary information presented in the textbook to their rule. Teacher B suggests that the children, after they have hardly found a word with a new orthogram, write down the words with silent consonants at the teacher's dictation and try to find them. From the methodological point of view, selective dictation at this stage is not only unwise, but very harmful. Many children find it difficult to complete the teacher's assignment and make mistakes: they still do not know how this spelling problem is solved. In addition, the teacher dictates words that are not part of the active vocabulary for many primary schoolchildren (lestniy - in English "flattering", okrestniy - "neighbouring", trostnik - "cane"), and therefore it is difficult for them even to determine their lexical meaning. Then, the teacher poses an unexpected question: "Who has figured out how to check the writing of silent consonants?" After that, the teacher with the children tries to formulate the rule, and finally makes them read the article.

As the result, the comparative analysis of two lessons demonstrates that the effectiveness of the Russian language teaching cannot be ensured only by the psychological and pedagogical competence of teachers. Even if a teacher is fully aware of the essence of the activity approach, knows the lesson structure based on the activity paradigm, the content of each stage of the lesson, this is not enough to implement effective teaching of the Russian language on the activity basis. It is the linguistic and methodological competence that allows a teacher to be effective in teaching a subject and in ensuring the new quality of education.

The experimental base of the research was Kazan (Volga Region) Federal University. The experiment was conducted in three stages. At the acknowledgement stage of the experiment, the knowledge of linguistic and methodological competence among primary school teachers and students, as well as the practice of developing this competence in the context of university and teacher advanced courses were analyzed; the formation of linguistic and methodological competence among teachers and students was studied. At the formative stage, strategies for the competence development in relation to teacher education programs were tested. At the control stage of the experiment, the obtained results were analyzed, conclusions were drawn.

\section{Results}

\section{Acknowledgement stage of the experiment}

Planned attendance of advanced training courses in 2019 on the basis of the Kazan Federal University. 290 primary school teachers of the Republic of Tatarstan took part in the survey. Schools offer a variety of 14 advanced training programs, which included programs on the improvement of certain competencies of teachers. Teachers had to choose the focus of training that they needed most (without reference to the course dates and location). Top five most popular courses among primary school teachers are: 1) Improvement of primary school teachers' subject competence (15\%); 2) Improvement of primary school teachers' methodological competence (12\%); 3) Improvement of primary school teachers' subject, methodological, psychological, pedagogical, and communicative competencies (14\%); 4) Development of primary school teachers' skills for improvement of meta-subject skills in students (15\%); 5) Development of primary school teachers' assessment skills (9\%). Thus, the survey demonstrates that teachers need to improve their subject and methodological skills. The professional activity of primary school teachers is multi-subject. Hence, teachers had to determine their particular methodological abilities. Among four 
subjects (mathematics, Russian, reading, environmental studies), the Russian language was chosen by $64 \%$ of the respondents. The subject (linguistic) and methodological competencies in the sphere of Russian language teaching are taught on the basis of linguistic and methodological competence. This survey demonstrates the teachers' need to develop and improve their linguistic and methodological competence.

To determine the level of linguistic and methodological competence, we have developed a diagnostics. Fourth-year bachelor's students majoring in primary education and English (69 people), as well as primary school teachers (72 people) who completed advanced training courses at the Kazan Federal University were involved as respondents. To assess the development of linguistic and methodological competence within the stated competencies, an average scale was applied: 1-30\% (low level); $31-65 \%$ (average level); 66 - 100\% (high level). For diagnostics, we have developed tasks that check the level of competencies which are part of the linguistic and methodological competence. Tasks of different levels of complexity were included. The analysis of diagnostic examination results led to the conclusion that the majority of respondents had a low or average level: $48 \%$ of students had a low and $43.5 \%$ of students had an average level of linguistic and methodological competence (Fig. 1), among teachers - low level (35\%), average level (44\%) (Fig. 2).

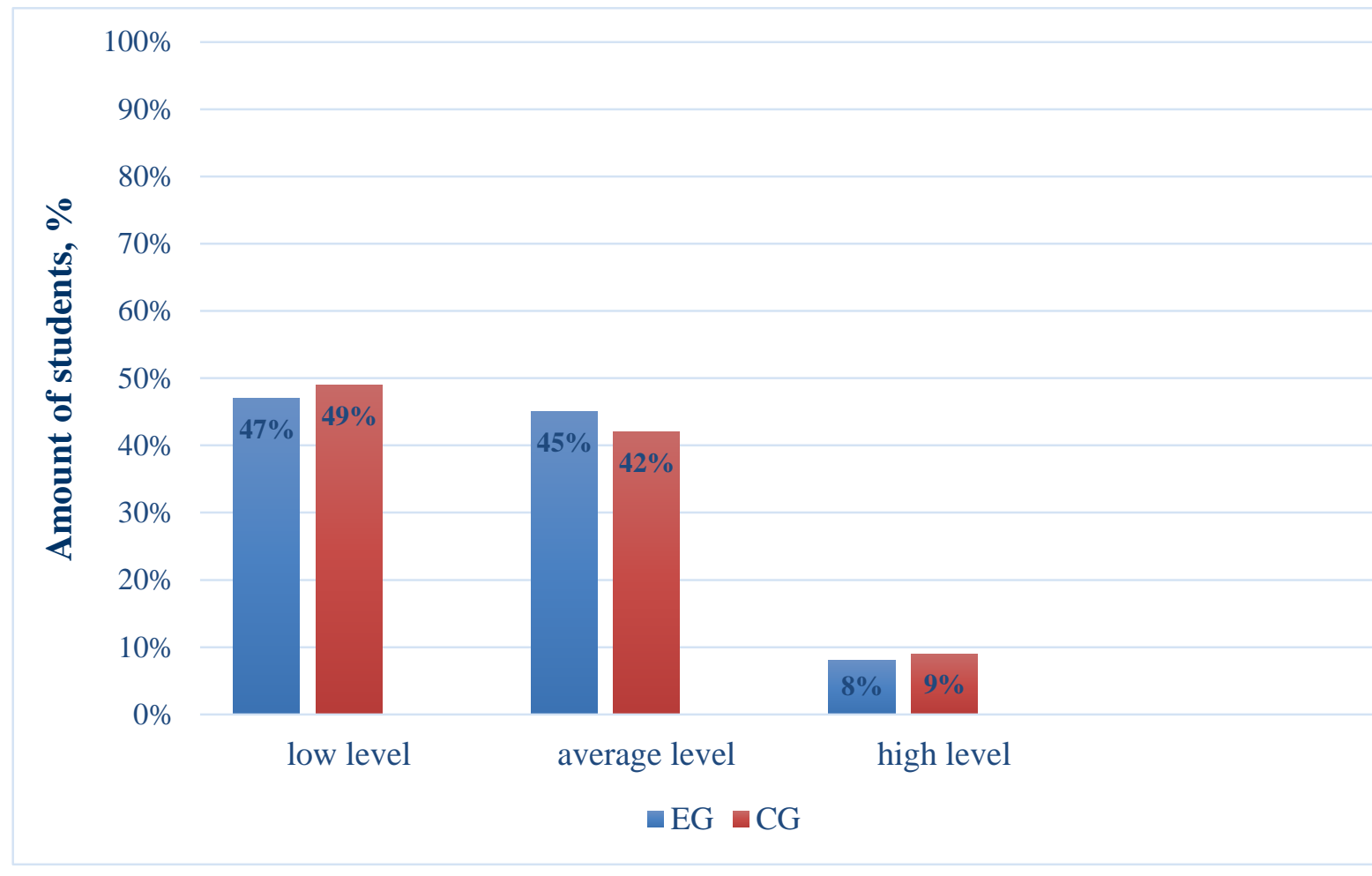

Fig. 1. Results of students' linguistic and methodological competence at the acknowledgement stage of the experiment 


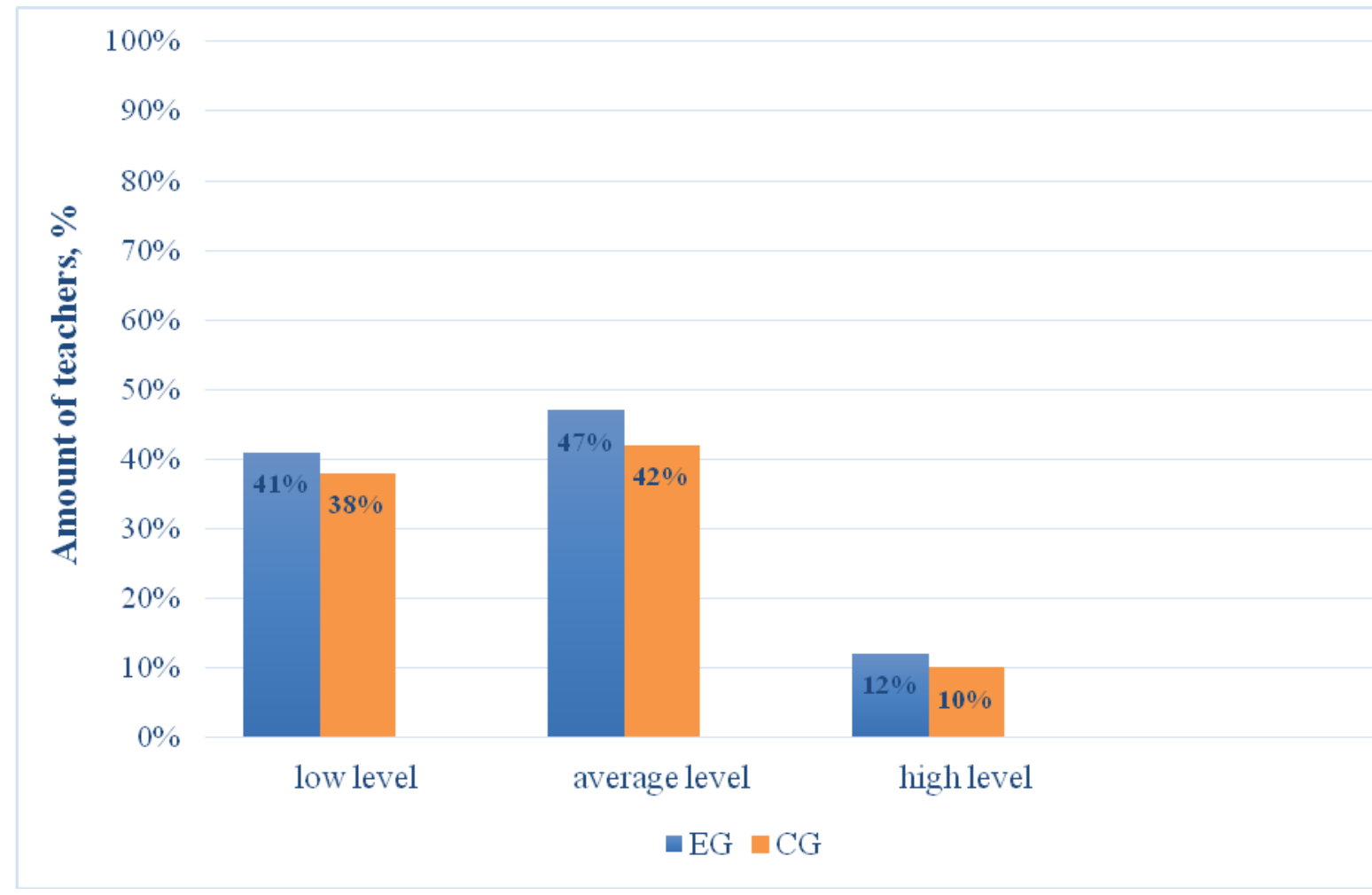

Fig. 1. Results of teachers' linguistic and methodological competence at the acknowledgement stage of the experiment

\section{Formative stage of the experiment}

When we were choosing strategies for the linguistic and methodological competence development, we relied on the Isaeva's study (2016). We consider it possible to use two key strategies for forming linguistic and methodological competence developed by the scientist - cognitive and projective, in the process of teaching both students and primary school teachers in advanced training courses. The methodological basis of strategies is made up by competence and system and activity approaches implemented through the use of interactive technologies.

The cognitive strategy (learning strategy) is aimed at mastering basic competencies that provide theoretical and methodological basis of professional pedagogical activity. The cognitive strategy of linguistic and methodological training is related to linguistic and particular methodological competencies. Projective strategy (action strategy) is aimed at mastering practical competence, ensures the acquisition of professional experience. This strategy correlates with projective, performance, information-representing and control-evaluative competencies.

The choice of cognitive strategy raises no questions when it comes to the linguistic and methodological training of bachelors. The solution of many professional tasks is largely determined by the level of linguistic and methodological teacher training. For example, for many teachers it is not difficult to list schoolchildren's spelling skills. However, when moving to the next level of mastering the concept (I apply), problems start to appear. Thus, during the task (match the textbooks exercises with the formed orthographic concepts), both students and teachers made a mistake by including the exercise on mastering 
a positional principle of graphology (positional way of sound transcription as a letter) in the system of orthographic exercises. The methodology offers a different system of tasks for the formation of orthographic skills and mastering the principles of Russian graphology. The effectiveness of teaching children the norms of written speech depends on a teacher's competent choice.

We describe the tactics with the help of which these strategies can be implemented. Technologies, methods, tools will be considered as tactics for implementing these strategies.

We suggest implementing the cognitive strategy in distance teacher training which is now offered by all advanced teacher training courses in the Republic of Tatarstan. They are different in time and depend on the category of teachers. Working in the distance mode, a teacher can build an individual trajectory of his/her learning, choosing an appropriate module with theoretical and practical units. We determined the module contents which ensure the development of linguistic and methodological competence. The module's theoretical units include lecture notes, video lectures, presentations, etc. The practical unit contains tasks of three levels (I know; I understand and apply; I interpret and design). Teachers can choose the level of tasks they perform and do this unit in different ways. Modules with theoretical and practical units are differentiated according to the competencies they form (linguistic, methodological). The selection of tasks can draw on the results of input diagnostics, which allows teachers to identify problem areas of their professional activities (including methodological).

We primarily associate projective strategy in the context of teacher training with practical sessions with teachers. Teachers of different qualification categories attend the courses and we took into account this fact when we developed the tasks and organized the educational process in class. Technology was cooperative learning. The groups were formed considering the techniques developed in this technology. For example, it could be like this: groups 1 and 2 were strong teachers (the highest qualification category) and groups 3 and 4 were teachers without a category and with the first qualification category. Various types of work with lessons scenarios, video tutorial materials were used. The groups used the materials of two lessons which were analyzed at the beginning of the article. Groups 3 and 4 had to perform a comparative analysis of two lessons according to specified criteria (lesson structure with regard to the activity approach, stages of knowledge actualization, their effectiveness, connection with the new topic, language material of the lessons, creation of the problem situation in the lesson, work with texts, etc.). Teachers of Groups 1 and 2 had to improve the teacher B's lesson and bring it to a new level of linguistic and methodological literacy, of the consistent implementation of the activity-based approach in the lesson.

In addition, a case study method was used. We consider a case study as a particular practical situation, specially developed on the basis of factual material for the purpose of further analysis in a training session with teachers, and relevant for making a methodological decision. A model scenario of training sessions with the use of case studies: 1. Acquaintance stage. Teachers' involvement in a lively discussion of a real professional situation: introduction, description of a situation, information material, glossary. 2. Main (analytical) stage: teacher's opening words, division of students into groups, organization of group work, the first round of discussion - discussion of a problem in small groups, search for arguments and solutions, the second round of discussion - presentation of the analysis results, group discussion, discussion summary. 3. Final stage: final presentation of the analytical work results summarising teacher performance, i.e. the situation analysis, assessment. The assessment took into account the wholeness of the problem solution, presentation skills, clarity, and originality of the solution and the results presentation.

One of the weak points of teachers' linguistic and methodological training (according to the survey and entry diagnostics) is information and presentation competence, which is understood as an 
ability to use the capacities of information environment in teaching. Today, digital educational resources are actively developing in Russia (Uchi.ru, Yandeks.Uchebnik, Kahoot, Learning.app, etc.). Teachers' regular use of digital educational resources (hereinafter referred to as "DER") in the Russian language lessons significantly increases the motivation and involvement of primary schoolchildren in the educational process, the effectiveness of teachers' feedback to ensure that students' cognitive characteristics and individualization of the educational process are taken into account. Therefore, working with teachers within the course training, it is necessary to identify and work out effective practices of using DER in the process of teaching the Russian language to primary schoolchildren. In this regard, a project method seems productive: teachers carry out projects on a given topic.

Information and presentation competence is better formed among students than teachers, since it is consistently and systemically developed at the university. During the formative stage of the experiment, students organized masterclasses for teachers on the use of DER in teaching the Russian language to primary schoolchildren. Active forms of interaction between teachers and students, such as workshops, joint round-table discussions, and seminars contribute to the development of an axiological component of the linguistic and methodological competence.

The following techniques are also used in the preparation of students for teaching Russian to elementary school pupils: cooperative learning, a case study and project methods. The structure of practical sessions may be different and depend on the used technology. At the same time, it is possible to identify the invariant parts of the majority of lessons: motivation, problem statement and formulation of the topic and objectives of the lesson, self-guided work with self-examination, reflection. On the basis of the conducted reflection, each student formulates learning goals for the next lesson or for self-guided work at home. At this stage, a student understands what linguistic knowledge he/she lacks to solve methodological problems successfully and what methodological provisions need to be improved and more thoroughly studied.

An irreplaceable tool for the formation of students' linguistic and methodological competence is a digital educational resource developed by the author of the article (hereinafter referred to as DER) for the discipline "Methods of teaching Russian in primary school" which was used in the work with students at the formative stage of the experiment. It provides both materials for self-study (lecture notes, video, audio lectures, articles, etc.), and materials for students' practical activities (video lessons, methodological tasks, articles, etc.), as well as control means (tests, control papers, themes for project works, etc.). The assignment results can be discussed in the chat with the teacher and other students within the framework of DER. This increases the learning potential of this educational resource: students not only identify their mistakes, but also, having discussed the problem in the chat, understand why the answer should be different and how they should have thought and acted. Serious questions and problems on the methods of teaching Russian to primary school students can be discussed in a forum format. The work with the DER increases students' motivation to study the subject, it is also effective as a tool to make bachelor's individual learning path, which generally improves the efficiency of the linguistic and methodological competence development among future primary school teachers.

\section{Control stage of the experiment}

At this stage, diagnostics were carried out to determine the dynamics of teachers' and students' linguistic-methodological competence formation. We used the same methods as the ones at the acknowledgement stage of the experiment. The data from the control assessment showed positive dynamics in both control and experimental groups. However, the positive dynamics are more obvious 
among students and teachers of the experimental group. The number of students and teachers with high and average levels increased.

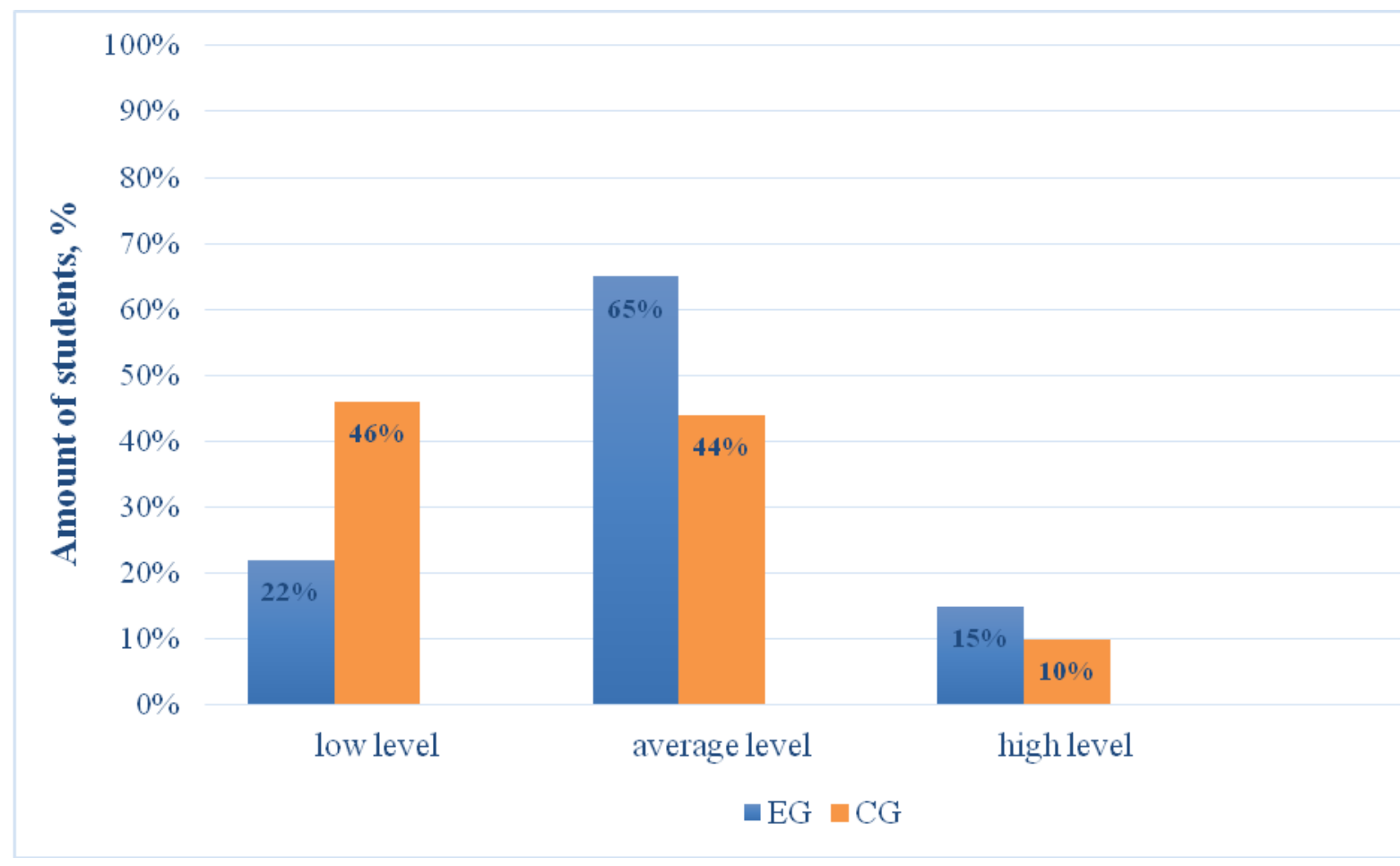
experiment

Fig. 3. Results of students' linguistic and methodological competence at the control stage of the 


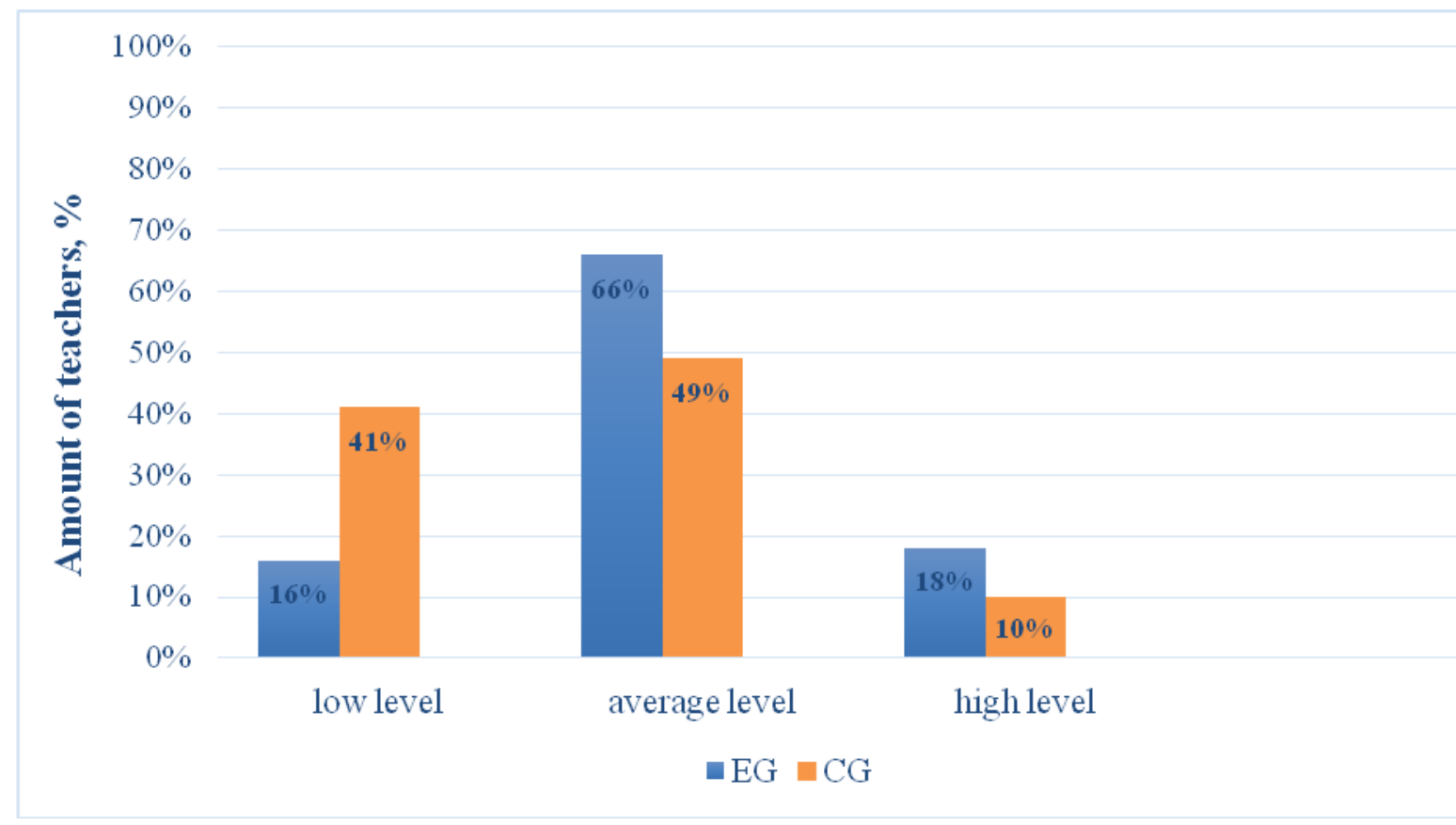

Fig. 4. Results of teachers` linguistic and methodological competence at the control stage of the experiment

Thus, in the course of experimental work, it was possible to achieve the increase in the level of linguistic and methodological competence formation among the majority of teachers and students.

\section{Discussions}

The study of psychological, pedagogical and methodological literature allows us to state the lack of special studies on the problem of primary school teachers' linguistic and methodological competence development in the context of continuous pedagogical education. However, the formation of linguistic and methodological competence among language teachers is considered in many aspects in the works of Streltsova (2004) and Ostrikova (2014). A comprehensive analysis of the content, structure and characteristics of primary school teachers' professional methodological activities in the field of language training is conducted in the works of Soloveychik (2000), Sosnovskaya (2008) and Zinovyeva (2011).

Analysing development prospects in the field of future teachers' linguistic and methodological training, Deykina (2011) determined a direction of its development - development of the theoretical foundations for a new field of scientific knowledge - university training of methods for teaching Russian at school.

\section{Conclusion}

It has been established that the formation of linguistic and methodological competence among students and its improvement among primary school teachers will be effective if cognitive and projective strategies are implemented in university programs and in advanced training courses for teachers. The use of the activity type technologies in the learning process, use of methodological tasks as a tool for problem situations modelling and as a means of learning, use of distance learning opportunities for teacher training 
individualization during the course preparation, development and use of a digital educational resource on the discipline allow to make the process of primary school teachers' linguistic and methodological competence formation and development in the context of continuing pedagogical education more effective and efficient, and the process of bachelors preparation as practice-oriented as possible.

\section{References}

Avalos, B. (2011). Teacher professional development in Teaching and Teacher Education over ten years. Teaching and Teacher Education, 27, 10-20.

Deykina, A. D. (2011) Trends in the development of the Russian language teaching methods. Russian Language at School, 6, 4-8.

Guerrero, D., \& La Rosa G. (2013) Scientific Domain Analysis of Professional Competences, ProcediaSocial and Behavioral Sciences, 92, 369-376.

Isaeva, N. A. (2016). Modern strategies of linguistic and methodological training for bachelor's students of teacher education programs (with the Russian language major). $\mathrm{PhD}$ Thesis, Moscow.

Kurlygina, O. E. (2012). Methodological task as a means of primary school teachers' linguistic and methodological competence development. $\mathrm{PhD}$ Thesis, Moscow.

Lvov, M. R. (2007). Russian language at school: History of teaching: A course of lectures for students of pedagogical schools and colleges. Moscow: Verbum-M.

Opfer, V. D., \& Pedder, D. (2011). Conceptualizing Teacher Professional Learning. Review of Educational Research, 81(3), 376-407.

Ostrikova, T. A. (2014). Brief analysis of educational and professional literature on the methods of teaching the Russian language in the context of students' personal development. In E. A. Ryabukhina \& V. D. Yanchenko (Eds.), Modern methodological concept of students' personal development in the process of learning the Russian language. Perm: OT i DO.

Sinichkina, N. E. (2010). Formation of linguistic and methodological competence of future teachers of the Russian language in a modern university. PhD Thesis, Veliky Novgorod: INPO Yaroslav-theWise NovSU.

Soloveychik, M. S. (2000). Russian language in primary school. M. S. Soloveychik (Ed.). Moscow: Academia.

Sosnovskaya, O. V. (2008). Theory of Literature and Reading Practice. Moscow: Academia.

Streltsova, T. V. (2004) On the issue of the Russian language teachers' research competence. Relevant problems of teaching the Russian language at the current stage of Russian secondary and higher education. Paper presented at the All-Russian Research-to-Practice Conference, Moscow, Russia.

Zinovyeva, T. I. (2011). Work on intonation during the period of literacy training. Moscow: Econ-inform. 